Purdue University

Purdue e-Pubs

2013

\title{
Technological Drivers in Data Centers and Telecom Systems: Multiscale Thermal, Electrical, and Energy Management
}

S V. Garimella

Purdue University, sureshg@purdue.edu

T. Persoons

University of Dublin, Trinity College

J.Weibel

Purdue University

L.-T. Yeh

Huawei Technologies

Follow this and additional works at: https://docs.lib.purdue.edu/coolingpubs

Garimella, S V.; Persoons, T.; Weibel, J.; and Yeh, L.-T., "Technological Drivers in Data Centers and Telecom Systems: Multiscale Thermal, Electrical, and Energy Management" (2013). CTRC Research Publications. Paper 188.

http://dx.doi.org/http://dx.doi.org/10.1016/j.apenergy.2013.02.047

This document has been made available through Purdue e-Pubs, a service of the Purdue University Libraries. Please contact epubs@purdue.edu for additional information. 


\title{
Technological Drivers in Data Centers and Telecom Systems: Multiscale Thermal, Electrical, and Energy Management*
}

\author{
Suresh V. Garimella ${ }^{a}$, Tim Persoons ${ }^{b}$, Justin Weibel ${ }^{c}$, Lian-Tuu Yeh ${ }^{d}$ \\ a School of Mechanical Engineering, Purdue University, 585 Purdue Mall, West Lafayette, IN 47907, USA, \\ E-mail: sureshg@purdue.edu (Corresponding author. Phone: (765) 494 5621) \\ b Department of Mechanical and Manufacturing Engineering, University of Dublin, Trinity College, Dublin, Ireland, \\ E-mail: tim.persoons@tcd.ie \\ c School of Mechanical Engineering, Purdue University, 585 Purdue Mall, West Lafayette, IN 47907, USA, \\ E-mail: jaweibel@purdue.edu \\ d Huawei Technologies, North American Headquarters, 2330 Central Expressway, Santa Clara, CA 95050, USA, \\ E-mail: Jjyeh2@aol.com
}

\begin{abstract}
We identify technological drivers for tomorrow's data centers and telecommunications systems, including thermal, electrical and energy management challenges, based on discussions at the 2nd Workshop on Thermal Management in Telecommunication Systems and Data Centers in Santa Clara, California, on April 25-26, 2012. The relevance of thermal management in electronic systems is reviewed against the background of the energy usage of the information technology (IT) industry, encompassing perspectives of different sectors of the industry. The underlying drivers for progress at the business and technology levels are identified. The technological challenges are reviewed in two main categories immediate needs and future needs. Enabling cooling techniques that are currently under development are also discussed.
\end{abstract}

Keywords - Electronics cooling; 3D chip packaging; Power utilization effectiveness; Total cost of ownership; Cloud computing; Alternative air movers; Liquid cooling.

\footnotetext{
"This paper is based on discussions at the 2 nd Workshop on Thermal Management in Telecommunication Systems and Data Centers, held in Santa Clara, CA on April 25-26, 2012, which was dedicated to Richard Chu, IBM Fellow Emeritus, for his $50+$ years of distinguished services and significant contributions to the heat transfer community. The authors offer this paper in memory and honor of his towering presence in the community.
} 


\section{Background}

\subsection{Statistics on IT energy usage}

The combined worldwide electricity consumption of data centers has increased from 71 billion kWh per year (in 2000) to 152 billion kWh per year (in 2005) [1] to approximately 238 billion kWh per year (in 2010) [2], representing a growth of roughly $11 \%$ per year over the last decade (Fig. 1). As a fraction of the worldwide total electricity usage for all sectors [3], the contribution of data centers has increased from $0.53 \%$ in 2000 and $0.97 \%$ in 2005 to $1.31 \%$ in 2010 . Based on electricity statistics by country for 2009, the overall electricity consumption of data centers is comparable to the electricity production of countries like Australia, Mexico, Saudi Arabia, and Iran [4,5].

The growing IT demand is outpacing technological developments in sustainable energy management for these systems. Between 2003 and 2008, the total energy consumption of servers has doubled, showing only a temporary slowdown during the global economic crisis [6]. Such growth levels are unsustainable, and are especially worrying because IT equipment already contributes significantly to global energy use and carbon emissions. For Australia in 2005, the equivalent carbon emissions of the IT equipment (comprising data centers and smaller distributed equipment throughout the commercial sector) amounted to approximately $1.5 \%$ of the country total [7]. Based on the same study, the carbon footprint of IT equipment is comparable to that of civil aviation and the metal industry (respectively $1 \%$ and $2.3 \%$ of the country total).

According to a study by The Uptime Institute, the average ratio of three-year site costs (comprising operational and capital costs) to one rack unit (1U) server costs has exceeded $100 \%$ as of 2005 and the projected increase is not tenable [8]. Most of the available statistics report on energy consumption as an operational expenditure. The energy cost is the fastest growing expenditure in data centers, currently averaging about $12 \%$ of the total operating cost [9]. From a holistic point of view, one should also look at the life-cycle cost comprising energy consumption of manufacturing, mining, materials processing, and recycling. Of particular concern are mobile and personal computing devices, with a rapidly growing market and a typical lifetime of only a few years. For such devices, indirect energy use, viz. in manufacture and end-of-life treatment, may account for over $50 \%$ of the total lifetime energy consumption according to a life-cycle assessment performed by the University of California Energy Institute [10].

In an average data center, the IT equipment itself (i.e., rack-mounted servers) uses only about half of the total energy, with the remaining $50 \%$ overhead being used for cooling and electrical power delivery [1,2]. The electrical power delivery losses arise from the uninterruptible power supply (UPS), several voltage conversions and electrical transport within the facility. External transport of electrical power and electronic data between the data center and the grid is not accounted for in typical energy usage statistics. The dominating factor in the $50 \%$ overhead is the mechanical cooling plant, accounting for roughly $33 \%$ of the total energy consumption of a data center facility. Figure 2 shows a Sankey diagram representing the distribution of the incoming power among the three main system components (IT equipment, system cooling and electrical power delivery). A number of sections of this paper that focus 
on particular aspects of this energy chart are indicated, with red text representing energy usage metrics (Sect. 1.2) and strategies for energy saving (Sect. 1.3), and green representing the cooling challenges and solutions discussed in Sect. 3 and 4.

\subsection{Metrics for IT energy management}

\subsubsection{Power Usage Effectiveness (PUE)}

The most commonly used descriptor of data center energy efficiency is the power usage effectiveness (PUE) proposed by the Green Grid initiative [11]. PUE represents the ratio of total power required to operate a system (including cooling, power distribution and other overheads) to the power used only by the IT equipment. PUE is the reciprocal of the data center infrastructure efficiency (DCiE). Symbolically,

$$
\mathrm{PUE}=\frac{P_{t o t}}{P_{I T}}=\frac{P_{I T}+P_{T}+P_{E}}{P_{I T}}\left(=\mathrm{DCiE}^{-1}\right)
$$

where $P_{I T}, P_{T}$ and $P_{E}$ are the power consumption of the IT equipment, thermal management system and electrical power distribution system, respectively.

Between 2000 and 2010, the worldwide average PUE value has favorably decreased only slightly from about 2.0 to a value between 1.83 and 1.92 (see Fig. 3) [1,2]. A study by the U.S. Environmental Protection Agency (EPA) [12] found an average PUE of 1.91 based on a voluntarily submitted survey of 120 data centers, which may represent an optimistic estimate of the actual average.

There is a wide variation in PUE between different data centers, as exemplified by the range of PUE values between 1.25 and 3.75 reported by the aforementioned EPA study [12]. The value depends not only on the type of cooling infrastructure (e.g., free cooling, mechanical cooling) and IT equipment (e.g., type of servers, spatial arrangement, primary cooling medium), but also on the geographical location and local climate around the facility. The lowest attainable PUE value for a given system depends strongly on the average ambient temperature available as the ultimate heat sink. For the majority of systems, the ultimate heat sink is the ambient air although in some cases nearby water streams or reservoirs are used because of their more stable temperature. One of the lowest PUE values on record is for a data center in the National Renewable Energy Laboratory [13] at PUE $=1.06$.

From a business point of view, striving for PUE values close to unity is beneficial in terms of reducing the percentage overhead operational cost associated with electricity consumption for non-computing purposes. However, capital investment costs tend to increase in a nonlinear fashion, with diminishing returns as PUE approaches 1.0, resulting in a trade-off which depends on the factors affecting the PUE as mentioned above. In recent years, Google has made significant efforts to decrease its company-wide PUE to about 1.14 (Fig. 3 [2]) but the benefits of further reductions do not warrant the costs, from an economic perspective. Yet, for a dominant presence such as Google to reduce the PUE slightly from 1.14 to 1.13 would mean a reduction in their total energy consumption of approximately $19 \mathrm{GWh}$ annually [2], or a reduction in total power consumption of $2.2 \mathrm{MW}$. 
While economic considerations may prevent further reduction of the PUE values toward 1.0, energy savings of a comparable magnitude may instead be realized through a shift in the governing objective to reduce the absolute value of energy consumption of the system (e.g., by increasing server utilization, or enhancing the energy efficiency within the server rack).

\subsubsection{Changing the definition of PUE}

The standard definition of the power usage effectiveness is somewhat simplistic and perhaps too restrictive, using only the most readily measurable quantities. Firstly, the IT electrical power consumption is taken at the input to the server racks. Therefore, power used by fans or other cooling devices inside a server rack is included in the IT equipment contribution, not in the thermal management contribution. This may result in misleading PUE values when racks with more intensive internal cooling are used. Secondly, some non-standard operational expenditures are not accounted for, such as energy expenditure in the treatment of river or sea water used for cooling, which may again result in misleading PUE values. Thirdly, the PUE ignores the embedded energy resulting from a life-cycle assessment of the equipment and infrastructure. Application of this kind of holistic approach is in its infancy, but it might present a very different picture that rewards lean manufacturing processes and operational sustainability.

Moreover, in the original PUE definition, the useful output is identified as the energy consumption of the IT equipment, yet the actual useful output is the computational power, which is commonly expressed in teraflops. Therefore, some authors have proposed a coefficient of performance [14] as an alternative to the DCiE metric,

$$
\mathrm{COP}=\frac{P_{I T}-P_{I T, \text { leak }}-P_{I T, \text { fans }}-P_{I T, \text { idle }}}{P_{T}+P_{E}+P_{I T, \text { leak }}+P_{I T, \text { fans }}+P_{I T, \text { idle }}}
$$

The energy consumption due to (i) transistor leakage power $P_{I T, l e a k}$, (ii) rack-internal cooling power $P_{I T \text {,fans, }}$ and (iii) idling power $P_{I T, \text { idle }}$ is subtracted from the IT equipment power consumption $P_{I T}$, leaving only the power consumption which goes to computational purposes in the numerator. The three overhead components are lumped together with the infrastructure power consumption (thermal management and electrical power delivery), so that the numerator represents the overall power overhead required to enable the computation to take place.

Other types of metrics have been proposed by HP to optimize data center operation, such as (i) a temperature-based thermal correlation index used to identify the zone of influence of a computer room air conditioning (CRAC) unit [15], (ii) air delivery efficiency metrics [16,17], and (iii) computational workload placement metrics [18-20].

\subsubsection{Energy cost per teraflop}

Energy-performance metrics are gaining importance for IT equipment, and are usually expressed in terms of the number of logic operations per unit energy, or number of logic operations per second per unit power. From 2006 to 2012, Intel Xeon ${ }^{\circledR}$ servers have maintained about the same level in terms of 
electrical power but the number of operations per second has increased nearly tenfold [21]. The improvement is largely CPU and platform-driven, so one way to achieve better efficiency is to upgrade old systems.

For instance, LRZ-Munich's high performance computing center uses $40^{\circ} \mathrm{C}$ water for cooling its servers to achieve free cooling (i.e., direct heat exchange between the primary cooling water and the outside air, without resorting to mechanical refrigeration) throughout the year, resulting in a PUE value of 1.15 [22]. For three successive generations of servers used in this facility between 2000 and 2012, the total power consumption increased six-fold, resulting in a commensurate increase in energy costs. However, the number of logic operations per unit energy increased nearly 400 -fold over the three generations of servers. As such, in terms of energy cost per teraflop, the system is currently operating at $€ 7 /$ teraflop compared to $€ 2,300 /$ teraflop in 2000-2006, although the total energy bill is still increasing to levels that are cause for concern [22].

Based on the current projections for supercomputers [23], computational performance approaching 1 exaflops (i.e., 1 million teraflops) is expected by 2019. Even with continued exponential growth of performance per unit energy, further developments are needed to avoid excessive power consumption levels.

The growing awareness about the energy use in IT equipment itself is encouraging. While striving for a PUE ratio close to 1, the absolute value of IT power consumption (i.e., the denominator in Eq. (1)) should not be overlooked.

While these general energy usage statistics and energy efficiency metrics for the IT industry focus on data centers, the conclusions broadly apply to telecommunication systems as well. Strategies for energy savings discussed below are relevant to both data centers and telecommunication systems.

\subsection{Strategies for energy savings}

\subsubsection{Alternative design and operating methodologies}

The American Society of Heating, Refrigerating and Air-Conditioning Engineers (ASHRAE) expanded the operating envelope for air-cooled data processing facilities to a broader range of temperatures [24], adding classes with a maximum rack inlet temperature up to $45^{\circ} \mathrm{C}$ (Class $\mathrm{A} 4$ ) in 2011 , whereas the previous maximum allowable was only $35^{\circ} \mathrm{C}$ (Class $\mathrm{A} 2$ ) in 2008. For an air-cooled data center, operating the server room at elevated temperatures results in (i) the need for increased internal air flow rates within the racks (e.g., higher average fan speeds) to compensate for the higher air inlet temperature, and (ii) a higher heat transfer potential to the outside ambient air. For a typical data center, the overall net effect is a reduction of the infrastructure energy consumption.

The challenge is to engineer platforms with a full range of components capable of performing reliably and consistently at the warmer temperatures. To safeguard reliability and avoid overheating issues, advanced operating methods can take advantage of the instrumentation already available on a typical server platform. Current volume servers (i.e., a computer server packaged in a $1 \mathrm{U}$ or $2 \mathrm{U}$ high rack-mount 
chassis, typically fitted with up to four processor sockets [25]) have over 50 temperature sensors on board, spread out over various components and the motherboard.

A three-fold strategy is recommended by Google for achieving radically stripped down air-cooled data centers: (1) manage the air flow by metering flows and separating cold and hot streams, (2) optimize the efficiency of the mechanical cooling plant (i.e., the largest overhead component in the thermal management system) using advanced economizer design, which enables $80 \%$ efficiency (see Sect. 1.3.2), and (3) optimize the UPS system to an efficiency of $99.9 \%$ by trickle-charging battery banks.

Additional specific examples are given along with immediate and future challenges (Sect. 3).

\subsubsection{Alternative ultimate heat sinks}

The outside air temperature has a direct effect on the efficiency of the cooling system. However the air temperature in any location exhibits strong fluctuations in time (both day to night variations and average daily temperature variations throughout the year), even in temperate, maritime and colder climates. As such, it may be desirable to use other ultimate heat sinks with a more stable temperature level, such as large water reservoirs (e.g., seas, lakes, and rivers).

For instance, Google uses this approach for some of their data centers: using a river-fed water-side economizer in Saint Ghislain, Belgium; using an economizer with water sprayed over wetted media in Dublin, Ireland; and using sea water from the Bay of Finland in Hamina, Finland. In all cases, the servers are operated at the maximum possible air inlet temperature, to take advantage of the maximum possible temperature differential. This allows free cooling without the need for mechanical chillers.

Use of sea water for cooling poses challenges, although corrosion risks can be limited using plastic piping. Care should be taken to limit the temperature of the discharged water after passing through the heat exchangers so as to avoid adverse effects on the ecosystem.

\subsubsection{Alternative energy supplies}

To replace, back up or supplement traditional (electrical) power supply, several alternative energy sources could be considered. Thermoelectric generators could help to recover some energy from waste heat, or fuel cells could be used to generate power locally from alternative sources; both approaches typically have low overall generation efficiencies, but may utilize otherwise wasted energy sources. Depending on availability, renewable energy sources could be attractive in certain regions, yet most of these sources are inherently intermittent. Integrated thermal storage solutions using $\mathrm{CO}_{2}$ heat pumps might help to increase the potential for electronics thermal management, resulting in an intermittencyfriendly data center [26]. From among the myriad potential options, the viability of specific alternative electrical energy sources depends on a number of interconnected and time-varying technical, geographic, economic, and political factors, and is likely to be determined on a case by case basis. Hence, discussion of specific alternative options is outside the scope of this article. 


\subsubsection{Alternative uses for waste heat}

Space heating accounts for about $24 \%$ of the worldwide energy consumption [3], so there is significant potential for reusing waste heat from IT equipment to supply part of this heating demand. The main challenge is not so much technological, but rather in the logistics of identifying the value of heat and finding the most suitable customers within reasonable distances from the data center locations.

There are regional differences in the value of heat, because of climate, available infrastructure and population density. In Europe, heat is worth about 16 Eur/GJ (with a total district heating energy supply of 397,000 GWh in 2009) [27] which is roughly half of the average price of electricity in Europe (0.092$0.12 \mathrm{Eur} / \mathrm{kWh}$ in 2009) [28]. Because of the abundance of urban district heating systems, finding customers is relatively straightforward. There are no clear cost models for heat, but its value scales with the temperature difference between the transport medium and the local ambient temperature. As such, heat has a higher value in cooler climates for space heating, but it can have alternative uses in hotter climates as well, e.g., desalination of sea water, or for space cooling using adsorption chiller systems. Heat can be efficiently transported over distances of several tens of $\mathrm{km}$, with a linear loss with distance. Losses are generally about ten times higher than for a comparable power level of electricity.

From this perspective, improvements in exergy efficiency can mean savings in operating cost [29]. From a design perspective, recognizing the value of heat can lead to a completely different optimum. The dissipated heat can be taken from the core of the IT equipment using liquid cooling, transported in the same form to nearby customers and sold as heat, bypassing air cooling altogether. By collaborating with urban development authorities, new integrated ecosystems could emerge around data centers.

\section{Drivers for progress}

The driving forces underlying the further development of data center thermal management are reviewed, at the business (Sect. 2.1) and technology (Sect. 2.2) levels. This summary reflects the topics of discussion at the 2nd Workshop on Thermal Management in Telecommunication Systems and Data Centers in Santa Clara, CA on April 25-26, 2012. The tag cloud in Fig. 4 represents the keywords brought up during the panel discussions.

\subsection{Business level: Impact of energy usage on strategic plans}

Recent years have seen a shift in engineering focus towards the data center infrastructure, whereas previously the focus was on the IT equipment with cooling provided in an ad hoc manner. In terms of power density, we have reached a crossroads with two opposing directions: (i) increasing power density for high performance computing where the dominant cost is attributed to interconnects and communication between processors and memory, and (ii) lower density systems for cloud computing operations, possibly limited to 8-14 kW/rack to enable free cooling. The decision on which direction to pursue is determined by the balance between investment cost and energy cost. Even with a continued exponential improvement in cost efficiency (computational performance per unit energy), the total 
energy consumption is expected to rise, based on the experience over the past decade (Sect. 1.2.3). Server energy use has doubled between 2003 and 2008, with only a temporary slowdown due to the global economic recession [6]. As this growth continues and energy costs exceed investment cost, a shift in paradigm will arise. Currently, major companies such as IBM are literally creating hot air for an energy bill worth hundreds of millions of dollars, which is an important driver in examining alternative methods of reducing this expenditure or recovering some of the lost exergy.

\subsubsection{Total Cost of Ownership (TCO)}

The ultimate bottom line to operating a successful business is the compounded cost over the life time of operation, comprising capital investment and operational cost, i.e., the total cost of ownership (TCO). Any technological breakthrough must answer to this criterion. The challenge in getting a comprehensive estimate of cost for operation of a data center is that cost can be moved between IT equipment and infrastructure, and as various investment decisions are made at different times, this can lead to confusion about cost allocation.

As the most commonly used efficiency metric for data centers, the power usage effectiveness (PUE) is related to the TCO. However, the relationship between PUE and TCO is not straightforward, and the definition of PUE itself may need to be updated (Sect. 1.2.2). For a complex operation like a data center, there is a need to develop better TCO cost models. A composite model would be more useful than a single value metric such as PUE.

So although TCO is arguably the main driver behind corporate strategic plans, it is not clear how the TCO cost model is affected by quantifiable parameters (e.g., energy prices, equipment and infrastructure cost) and other less quantifiable aspects (e.g., public perception and legislation).

\subsubsection{What drives corporate strategies?}

In a rapidly evolving IT market, it is crucial to outline corporate strategies to try to match future customer demands. Companies like Intel employ futurists to help predict what end users will be expecting in the next decade and beyond [30], such as the evolution towards the wide range of form factors seen today, or the rapid expansion of the population carrying mobile devices that has surpassed $75 \%$ of the world's inhabitants [31].

As an example of the complex nature of TCO and corporate strategies, Google has been striving towards a zero carbon impact philosophy, offsetting its carbon footprint by buying green energy. Choosing this more expensive green electricity supply seems to be based on more than short term monetary benefit, and reflects the complexity of IT market strategies and evolving public demands. The subjective value of public perception in achieving the lowest PUE value in data centers is an open question.

In reality, achieving a lower PUE value is still a powerful force in driving down overhead cost. With the transition towards cloud computing come new opportunities and new challenges. The introduction of the new ASHRAE standards [24] has led to increased dialog between data center operators and server designers. Instead of using off-the-shelf servers, the servers are reduced to bare-bones cloud-optimized 
systems, striving for self-healing IT equipment instead of relying on concurrent maintenance. The infrastructure should be resilient and capable of handling increased variability of inputs. The cooling system and servers are co-designed to reduce the energy consumption cost. The aesthetics are not important; what matters is trading redundancy for resilience. The economics of data center operations is moving away from mainly capital expenditure ( $C a p E x)$ investment-driven costs to more operational expenditure $(O p E x)$ or energy-driven costs. As a result, there is a shift in focus towards optimizing the overall, integrated system encompassing the IT equipment and utilities, rather than focusing only on component-optimized designs.

This strategy is exemplified in some of Microsoft's largest data centers to date:

- Dublin, Ireland (30,000 m², $22 \mathrm{MW})$ using air economizers without the need for mechanical chillers, which is scheduled for expansion [32] in 2012 with an additional 10,000 $\mathrm{m}^{2}$ and $13 \mathrm{MW}$.

- Chicago, IL (65,000 $\left.\mathrm{m}^{2}, 60 \mathrm{MW}\right)$ [33] comprising only stacked containerized units. Unlike the facility in Dublin, chillers are still needed to cover the hottest days, but free cooling is used, outside temperature-permitting.

- Quincy, WA $\left(46,000 \mathrm{~m}^{2}, 27 \mathrm{MW}, \mathrm{PUE}<1.2\right)$ features a modular containerized design with a roof to protect from the elements, using only outside air and evaporative cooling [34]. The location is chosen partly because of cheap electricity prices due to the nearby Columbia River hydroelectric power plants. The Boydton, VA facility also uses adiabatic (evaporative) cooling instead of chillers.

In this same mindset, future data centers might become more physically integrated with utilities such as electric power plants, opening up alternatives for combined cycle generation, or using alternative forms of energy such as gas-powered fuel cells instead of electricity, that take advantage of a reliable gas supply. The scale of cloud computing might be a determining factor in pushing this evolution.

Although liquid cooling makes sense technologically as a superior heat transfer/transport medium in comparison to air [35], without reusing waste heat it does not make sense from a business perspective for companies like Microsoft and Google. They have chosen to reduce the infrastructure to the bare essentials, following the above strategy. However for alternatively aimed, emerging high-performance, high-density computing technologies [21], liquid cooling may prove to be a more viable option based on the TCO decision criterion.

Historically, the volume server business was controlled by a few companies with near-complete control) on technology development. Cloud computing has made the landscape more flexible. This evolution towards a self-organizing organic market affects even the larger players in their decision-making. While this seems like a natural tendency, care should be taken not to rely solely on random evolutionary mutations of technology. A reluctance to invest in radically new technology, preferring instead wellknown air cooling technology in barebones systems, might not prove to be the most profitable longterm solution. Although cloud computing may work to reduce the risk of technology monopolies, in doing so it also risks a narrowing field of view and an industry-wide reluctance to invest in new ideas.

Encouragingly, there is evidence for investment in developing revolutionary technology, both in industry (e.g., IBM) and in academic and government research agencies (e.g., DARPA). If these developments 
lead to significant cost reductions and performance gains, especially in the face of a growing cost of energy, cloud computing - by its very nature - will assimilate these changes.

\subsection{Technological level}

\subsubsection{Balance between computation and communication costs}

Arguably the main fundamental technological driver for technological progress is the balance between energy costs for computation and for communication. This balance applies both to the macro level (e.g., cloud computing versus local computing) and the micro level (i.e., the evolution towards 3D chip packaging).

The relative contribution of energy costs for communication is strongly affected by the system size. An analysis by IBM [36] shows that $99 \%$ of the overall energy consumption in an IT system goes toward communication, with only $1 \%$ being used for computation. Three decades ago, this ratio was close to a more sustainable 50/50 ratio [37]. In a typical air-cooled system, about 1 part per million of the volume is taken up by transistors and $96 \%$ of the volume is used for thermal transport. As communication costs become more important, so does this $96 \%$ waste in system volume. A liquid-cooled system has smaller system volume demands, making it an enabling technology for 3D chip architectures and higher system transistor density.

\subsubsection{Macro level: Cloud versus local computing}

The growing market for mobile handheld devices (e.g., smart phones and tablets) has led to increased data traffic, with only a limited amount of computing performed locally and the majority accomplished remotely in the so-called 'cloud' environment. This evolution should be seen in the context of the balance between computational and communication cost. Currently almost all the processing for a mobile phone is done in a data center, because the costs for transporting 'electrons' are not dominating yet, although transport may use up to $99 \%$ of the overall energy [37]. The processing itself could be done very efficiently in a small-scale integrated system, but would need to be driven by increased communication costs. In this context, IBM has proposed sugar cube-sized liquid-cooled systems to maximize computational efficiency. The balance between communication and processing cost will invoke a new balance between local and remote computing. In the future, the balance will most likely be much more energy cost-dominated (which may, for example, even lead to data centers being collocated with power plants to minimize energy costs). As either the cost of energy increases, and/or the data transfer volume increases, the balance might shift away from cloud computing towards more local computing.

If ultra-high density systems like IBM's sugar cube concept take hold and can be implemented in handheld systems, the dependence on remote computing may be reduced. However, if these performance levels become readily available in a cost-competitive manner, data centers of the era would again simply use a cluster of such devices for maximum computational performance. This highlights the positive feedback paradox that may eventually evolve to the same balance as exists today. 
The inevitable latency of a cloud system could be avoided by increasing local computing, but some mobile applications will likely always have higher demands than what can be done locally.

Regarding the demand for high performance computing (HPC) in scientific research, the transition to cloud computing is reminiscent of the evolution towards minicomputers some twenty years ago, due to the stranglehold on large-scale HPC facilities by a few large players. As a result, research efforts were scaled down to what could be done on minicomputers, and investments in large-scale systems stalled. However, it is important that the engineering community continue to support new investments in largescale HPC, as these will enable the most demanding computations addressing grand-challenge problems that may not be achieved with even significant advances in cloud computing.

Figures 5 and 6 show two Sankey diagrams representing two extreme cases: (1) a 'cloud-optimized' data center employing air cooling at elevated room temperature to make optimum use of free cooling (Fig. 5 ), and (2) a fully liquid-cooled data center designed to maximize waste heat energy recuperation (Fig. 6). As in Fig. 2, sections of the paper are indicated in the diagrams where relevant. For the cloud computing case (Fig. 5), the aim of companies like Microsoft and Google is to eliminate the need for mechanical cooling by operating at elevated room air temperatures, allowing these systems to quote very low PUE values. However as discussed in Sect. 1.2.2, these low PUE values do not account for an increase in power consumption within the racks due to more intensive air cooling.

\subsubsection{Micro level: Towards 3D chip packaging}

At the chip level, there is a similar disparity with the energy for communication between cores and memory outweighing that needed for computing operations. The main advantage of 3D packaging, or the vertical integration of chips with different functions (processors, memory, sensors, etc.) is to reduce the communication overhead. Since power dissipation depends on wire length, the energy consumption attributed to communication scales with the square of the system size. By combining the main memory and processor into a single stack, there is no longer a need for cache memory. This (i) reduces the communication latency, and (ii) reduces the energy consumption per floating point operation by more than an order of magnitude.

The evolution of information technology can be seen in two ways: (1) device-centric, where the device performance dominates and evolution is driven by the introduction of better devices, and (2) densitycentric, where communication efficiency dominates and evolution is driven towards denser, more efficient systems. This latter viewpoint is relevant for large systems at the petascale and beyond.

Looking at the evolution of IT equipment, the computational density (i.e., number of operations per second per unit volume) is increasing, as is the computational efficiency (i.e., number of operations per unit energy). As an example, the 2008 IBM Roadrunner system in Los Alamos National Laboratory [38] has reached a density of 1 gigaflops per liter at an efficiency of 0.4 gigaflop/J. By comparison, a human brain achieves about $10^{4}-10^{7}$ times more synapse operations per second per liter, at a $10^{3}-10^{6}$ times higher efficiency [39]. Although synapse operations cannot be directly compared to floating point operations, the volume- and energy-specific performance characteristics of IT equipment may be thought to be heading towards those of biological brains. 
The development of future high performance computing systems at IBM is very much density-centric, with a recent report [37] describing how to scale a 1 petaflops system in 10 liters. The comparison between biological brains and IT equipment can be taken a step further, in that a brain is hot-water cooled, and waste heat is used to raise the body core temperature to achieve better efficiency. The pumping power for the circulatory system, provided by the heart, is about $5 \%$ of the total energy budget; a similar level of overhead could be envisaged for such a bio-inspired IT system.

The most recent predictions for high performance computers [23] expect a peak computational performance per system of 1 exaflop per second to be reached by about 2019. Even with continued exponential growth of performance per unit energy, further developments are needed to avoid excessive power consumption levels. Even if the energy consumption per core does not increase, stacking will make for a more difficult thermal management challenge.

\subsubsection{Multidisciplinary opportunities}

In the traditional design process, each component is optimized individually. Only in an integrated design process that optimizes the system as a whole do transport costs become apparent and can affect the overall design optimal.

In terms of driving technological progress, there are typically more opportunities at the interfaces than at the cores of each technical field (e.g., thermal and electrical design; data center and utility operators). Some problems are poorly understood across boundaries which is where synergy is needed. The IT community is diverse and scattered, consisting of end users, data center operators, chip manufacturers, equipment integrators and others, and there is a limited understanding of the perspectives of each. Similarly, conventionally separate electrical design for power consumption reduction (via supply voltage reduction) and improved thermal management technologies have provided only incremental performance extensions to current approaches, whereas electrothermal co-design driven 3D architectures (Sect. 2.2.1.2) may provide more revolutionary gains.

An example of an inherited misconception relates to the operating temperature range for servers. The previous ASHRAE standards specified a very narrow temperature range, which dates back to the days of water-cooled systems when the room was air-conditioned to make it comfortable for people. When aircooled servers became prevalent, data center operators continued in the previous mode, using ever more powerful air conditioning units to maintain a comfortable working environment. The recent ASHRAE standards allow for a higher room temperature, which enables more energy efficient air-based cooling. This evolution has come about because of a closer dialog between data center operators and server designers.

\section{Immediate and future challenges}

A report by McKinsey \& Co. [40] highlights the importance of addressing the energy consumption of IT equipment in the framework of improving the energy efficiency of the U.S. economy as a whole. The report identifies the most important barriers to capturing this efficiency potential: (i) low awareness, in 
spite of IT equipment accounting for up to $25 \%$ of the electricity usage in the commercial sector, (ii) lack of understanding of energy efficiency compared to other attributes (e.g., price and technical performance), and (iii) poor procurement selection, partly due to misplaced focus on acquisition cost rather than lifecycle cost or scattered budgetary responsibility.

Although the energy consumption issue has been raising concern, it is not yet a dominant factor in the balance between computation and transport costs (see Sect. 2.2). However, it is expected that this balance will shift in the years ahead. This emphasizes the need to address challenges related to implementing more efficient cooling solutions for much denser packaging.

In terms of specific technological challenges, three-dimensional packaging and increasing density means that more developments are needed on the component level (e.g., high conductivity materials and thermal interfaces), as well as the rack and system level (e.g., fluidic and thermal couplings). Currently, air-cooled systems still represent over $95 \%$ of data center facilities, where an often overlooked challenge is acoustic noise emission.

From the point of view of designing a cooling system, a holistic approach is more appropriate than focusing on individual device optimization. Certainly for 3D packaging, electro-thermal co-design becomes very critical. One given approach (e.g., air or liquid) does not fit all needs, and continued developments are needed for both high-density (liquid cooled) and low-density (air cooled) approaches.

\subsection{Thermal and electrical challenges}

\subsubsection{A brief history of electronics cooling challenges}

Looking back in time, a high level of heat dissipation in itself does not necessarily pose a thermal challenge; rather, it is the heat flux which needs attention. In 1946, the Electronic Numerical Integrator And Computer (ENIAC) [41] built with vacuum tube technology used $174 \mathrm{~kW}$ of electrical power. However this only amounted to about $1 \mathrm{~kW}$ per square meter of floor space, so the thermal management focus was only at the room level.

As the power density increased, the focus shifted to rack cooling. By the mid 1970s to 1980, the first steps were taken towards thermal management inside the equipment, and the 1980s saw the introduction of liquid cooling of bipolar transistor processors [42], with a maximum bipolar chip power density of about $14 \mathrm{~W} / \mathrm{cm}^{2}$. After the transition from bipolar to CMOS technology, the period 1985-2000 was governed by enhanced air cooling, with a focus on smaller scales and hot spots. Now that the CMOS chip power density has reached a comparable level as in the bipolar transistor era of $15 \mathrm{~W} / \mathrm{cm}^{2}$, present and future chip-level thermal challenges will most likely involve (i) hot spots, and (ii) 3D packaging.

As an illustration of the challenge with hot spots, a $40 \times 40 \mathrm{~mm}^{2}$ quad core processor chip [43] with an average heat flux of $50 \mathrm{~W} / \mathrm{cm}^{2}$ can experience local heat loads up to $500 \mathrm{~W} / \mathrm{cm}^{2}$ causing local $30-40^{\circ} \mathrm{C}$ temperature spikes with thermal gradients up to $20^{\circ} \mathrm{C} / \mathrm{mm}$. The heat flux in these hot spots is about $1 / 10$ of that on the surface of the sun $\left(6,000 \mathrm{~W} / \mathrm{cm}^{2}\right.$ at a temperature of about $\left.5,500^{\circ} \mathrm{C}\right)$. However, the local heat transfer rate should be high enough to maintain a much lower temperature of about $100^{\circ} \mathrm{C}, \mathrm{a}$ 
level which would naturally occur at a heat flux of about $0.1 \mathrm{~W} / \mathrm{cm}^{2}$ (i.e., solar irradiation on Earth's surface).

Three-dimensional packaging has inherently more complicated thermal constraints, because for chips within the stack there is no direct conduction path to the outside of the package. The heat density problem has become volumetric, and there is no viable cooling solution that can dissipate the estimated volumetric heat generation levels. For example, $100-1000 \mathrm{~W} / \mathrm{cm}^{3}$ (at a temperature of $100^{\circ} \mathrm{C}$ ) [44] is comparable in terms of power density to a liquid metal-cooled nuclear reactor operating at 200-300 $\mathrm{W} / \mathrm{cm}^{3}$, yet at a much higher temperature level of $1400^{\circ} \mathrm{C}$. For historical comparison, a Cray-3 module had a power density of approximately $39 \mathrm{~W} / \mathrm{cm}^{3}$ at a temperature of $30^{\circ} \mathrm{C}$ using fluorocarbon immersion cooling [45].

Due to the limited available thermal solutions in this landscape, the focus of the next upcoming DARPA thermal management project [46] is on integrated microfluidics in manifolded liquid flow heat sinks, thermal interconnects, and thermal/electrical co-design. The main challenges identified by DARPA include (i) completing the inward migration of thermal packaging, (ii) extracting heat directly from the device, chip and package, and (iii) placing thermal management on an equal footing with functional design and power delivery. Further research is also needed into the physics of failure due to thermal cycling at elevated operating temperatures, which could significantly increase the driving force for cooling, as well as the available exergy for waste heat recovery.

\subsubsection{Component level: Challenges for 3D packaging}

As the computational performance of HPC systems continues to increase towards exascale computing, the communication bottleneck due to the physical distance between cores and memory becomes more critical, which is driving the development of 3D chip packaging.

In a traditional configuration with separate memory chips and a processor chip (with multiple cores and on-board cache) connected via a motherboard, the majority of the energy (99\%) is used for communication compared to about $1 \%$ for computation [36]. It takes over 1000 clock cycles to access the main memory. The main advantage of 3D chip integration is to increase the core-to-memory bandwidth by moving the main memory into the processor chip, thereby reducing the length of the connecting wires by several orders of magnitude. Several technological challenges related to novel IC packaging methods (e.g., distributed 3D stacks, 3DIC, and tiled dies) will need to be addressed [47].

In terms of electrical interfacing, different connection methods can be used (e.g., wire bonding, flip chip, 3DIC with through-silicon vias (TSV), or package-on-package) which could all achieve a total package height of less than $1 \mathrm{~mm}$ for use in mobile devices. The thermo-mechanical stress induced in these integrated packages will increase compared to traditional single-die packages. Interconnect reliability remains a challenge considering the increased electrical current density to power these high density integrated devices.

The optimal placement of memory and processor cores within the stack is important, and requires intimate co-design of thermal and electrical aspects and possibly splitting up high power components 
such as graphical processors into multiple units spread out across the stack. The thermal design will also need to compensate for height differences between neighboring components.

IBM's proposed solution consists of single-phase interlayer cooling with microchannel pin fin or other micro-structured heat sink layers, interwoven with silicon layers and electrically connected with TSVs that can be electrically insulated from water flow. IBM has been conducting studies on the potential failure modes and optimization for heat transfer performance for these configurations $[48,49]$.

\subsubsection{Rack and system level}

A power density of $20 \mathrm{~kW}$ per rack seems to be the threshold for most of today's air-cooled IT systems. Beyond this threshold, hybrid cooling can be used with selective liquid cooling for high power components and air cooling for the remainder of the equipment. Some examples include IBM's and Fujitsu's approach with microchannel liquid cooled heat sinks [50,51], the use of rear-door heat exchangers and multiple internal air-to-liquid heat exchangers to reduce the inlet air temperature for upper rack levels [52]. For the highest power density, full liquid cooling is being used by IBM in the Swiss Federal Institute of Technology (ETH) Zurich [53] and the Leibniz Supercomputing Centre (LRZ) [54]. Alternative methods such as using dielectric sprays in a sealed cabinet have been developed by Bell Labs and Purdue University [55].

\subsubsection{Robustness and reliability}

While rack operation in harsh environments may be motivated in some instances by reduction of overhead energy costs (see Sect. 2.1.1), there is a steep increase in growth of the telecommunications industry in developing countries where temperature/humidity control infrastructure is less prevalent. For these systems, performance becomes increasingly dependent on design for robustness and reliability. From a thermal perspective, heat transfer surfaces are particularly susceptible to fouling either by particulate matter loading or corrosion. Empirical quantification of performance reduction due to fouling is lacking, and when available, it is often tied to a specific geometry. While ASHRAE has defined standard particulate matter compositions for testing (Standards 52.1, 52.2), these are primarily motivated by the air filter industry, and may not reveal the actual thermal performance ramifications for a wide range of environments. Research in this area is required to (i) design surface geometries and coatings for reduced fouling and/or resilience to particulate loading, (ii) realize procedures for effective active and/or passive self-cleaning, and (iii) develop tools for predictive modeling of fouling processes.

\subsection{Acoustic noise emission}

\subsubsection{Applicable measurement and operating standards}

More so than other fields of engineering, acoustics is well covered by a number of standards. General acoustic noise measurement standards that apply to all products include ISO 3744 (referring to sound power levels in hemi-anechoic chambers) [56], ISO 3741 (referring to sound power levels in reverberation rooms) [57], and ISO 11201 (referring to emission sound pressure level at the location of 
the operator and bystander) [58]. Specific standards for IT products include ISO 7779, Ecma-74 and ISO 10302 for measurement of noise levels [59-61], and ISO 9296 for the declaration of noise levels [62].

Acoustic noise standards that prescribe emission limits include the Swedish Statskontoret 26:6 [63] and the European Telecommunications Standards Institute (ETSI) 300753 [64]. Although these are regional standards, they are adhered to worldwide by many industries.

Other noise exposure limits are enforced by legislation, such as OHSA regulation 1910.95 [65] which limits the maximum exposure to $90 \mathrm{~dB}(\mathrm{~A})$ for 8 hours and requires preventive actions for exposure to 85 $\mathrm{dB}(\mathrm{A})$ for 8 hours. European Directive 89/391/EEC [66] limits exposure to $87 \mathrm{~dB}(\mathrm{~A})$ for 8 hours, with lower and higher action levels at $80 \mathrm{~dB}(\mathrm{~A})$ and $85 \mathrm{~dB}(\mathrm{~A})$ for 8 hours, respectively.

The main source of acoustic noise in IT equipment is fans. The applicable measurement standard for fans is ISO 10302 [61], which gives the noise level as a function of fan load. However fan manufacturers typically only specify noise levels at a distance of $1 \mathrm{~m}$ away under zero load conditions, which is often too optimistic an estimate compared to realistic operating conditions.

\subsubsection{Acoustic challenges for air-cooled IT equipment}

Air cooling still remains an attractive thermal management solution for the majority of the IT industry, but the noise level must be reduced by developing high-performance low-noise fans. Noise production varies between fan types, and can be characterized by the intrinsic noise coefficient which is much lower for a centrifugal fan than an axial fan. However, acoustics experts believe that further gains in the development of quiet air-moving devices are very difficult to achieve; alternative solutions are discussed below.

Although there is some opportunity for noise reduction by careful fan selection, simultaneous demands of high flow performance and low noise emission are not easily reconciled.

The noise emission can be reduced passively, but this requires extra space for damping, which contradicts the objective of reducing floor space and communication losses. A possible scenario that would not affect floor space is to increase the rack height to free up space for acoustic damping. Passive acoustic damping at low frequencies is difficult, but effective attenuation of higher frequencies can be achieved with available methods such as acoustic doors.

Acoustic experts are skeptical about active noise cancellation in IT equipment. There are some cases where it might be appropriate but active cancellation remains very challenging for random noise. It also adds a significant cost, as well as the risk of amplifying noise if the controller phase control algorithm drifts.

There is some question about whether acoustic noise remains a primary concern for data centers. Since the new ASHRAE standards have elevated the maximum operating temperatures to $40-45^{\circ} \mathrm{C}$ at the inlet to the servers, this is no longer a worker-friendly environment, and noise reduction may not be relevant. Moreover, heat transfer is enhanced by strong turbulence, which indicates that the concomitant 
increase in noise generation in air-cooled systems is an unavoidable side effect of efficient cooling [67]. There might be room for improvement by alternative air cooling methods, as discussed in Sect. 4.1.

\subsection{Allocation of computation and server utilization}

Computational loads vary in time, both on a small scale at the chip level and on a large scale at a facility level. At the chip level, hot spots can change 1,000-10,000 times per second. Using information on the current computational load and the readings from embedded temperature sensors, core hopping can be applied (i.e., periodically swapping loads from hot to colder cores) in the millisecond cycle range [68]. For longer cycle times, liquid cooling provides a suitable means to switch between high to low cooling depending on computational load.

At the facility level, companies are striving to increase server utilization as the network capacity improves. However low utilization (less than 10\%) is not uncommon. A McKinsey report [69] concludes that data centers tend to focus on acquisition cost rather than lifetime cost, and may be overly concerned about reliability. In this risk-averse mindset, operators tend to overinvest in servers, resulting in low utilization. In typical circumstances, $30 \%$ of servers might have utilization levels of less than $3 \%$ and yet continue to contribute to the overall electricity consumption [69]. A combination of low utilization and a large number of servers means significant fluctuations in power demand (e.g., $500 \mathrm{~kW}$ fluctuations for a $200 \mathrm{MW}$ domain). Operating a data center at $50 \%$ utilization costs $2 x$ more than operating at the theoretical maximum of $100 \%$, but on the other hand, a certain margin is necessary for reliable operation. Virtualization is used for multi-server systems to optimally distribute loads and avoid underutilized servers.

\subsection{Electrical power delivery}

For data centers with traditional direct current (DC) power conversion and delivery systems, throttling the power demand results in poor efficiency. Instead, Google relies on their uninterrupted power supply (UPS) system to run out power spikes, using the batteries as an energy storage buffer. The same strategy can be used to deal with renewable energy sources on site, such as the wind farm near Google's data center in Hamina, Finland [70].

An alternative to using traditional lead acid batteries in UPS systems could be redox (reductionoxidation) flow batteries. These act as reversible fuel cells - storing electrical energy in an electrolyte solution - and their efficiency makes them suitable for storing large quantities energy, for instance for renewable power generation applications [71]. By pumping the electrolyte solution to within the chip itself, it could provide DC power at the low voltage required by the chip, while the spent electrolyte can carry heat away. This solution being considered by IBM can potentially lead to much higher efficiencies in the power delivery and thermal management system. Initial studies have shown that the pumping loss due to friction and fuel cell conversion losses would be significantly lower than the Joulean losses in an equivalent electrical power distribution system.

Today's power distribution systems contain many electrical down- and up-voltage transformations and DC/DC conversions. For a typical data center facility with three-phase $400 \mathrm{~V}$ AC incoming power, the 
efficiency is about $88 \%$ for the UPS system, $93 \%$ for the power distribution unit, $79 \%$ for the rack or server level power supply units, and $75 \%$ for the DC/DC voltage regulators that convert the voltage down to the chip level voltage [36]. These combine to a total efficiency of merely $50 \%$. Using a redox flow battery system, the total conversion efficiency from the incoming facility power to the chip voltage could be up to $70 \%$. This assumes an efficiency of $85 \%$ for the incoming AC voltage to DC conversion, $90 \%$ for the subsequent DC to electrochemical conversion, a small contribution due to pumping losses, and $90 \%$ for the electrochemical to DC conversion on the chip itself [36]. Such a hierarchical electrochemical system with a single macroscopic charging unit and multiple chip-level discharge units might satisfy the congruent demand for electrical power delivery and heat removal.

\subsection{Modeling}

Thermal simulation and thermal characterization are tools essential to evaluating and optimizing the thermal performance of electronic packages. Thermal characterization can provide a direct way to measure device or package temperature; however a comprehensive characterization of components can be too time-consuming and costly, especially at the data center scale. Furthermore, experimental uncertainty must be considered.

Advancements in software and computing speed make modeling and simulation an effective method in analyzing and predicting thermal performance. However, the uncertainty in material properties, and the simplifications and assumptions made in the modeling and simulation may impact the accuracy of the results. An experienced approach to combined use of both characterization and simulation can make up for the deficiency in each tool and provide realistic and accurate results.

Some aspects, such as acoustics, are particularly time-consuming to simulate. These require fourdimensional simulation of a turbulent flow field with time steps of less than 1 millisecond using a timemarching, weakly compressible, large-eddy simulation method [72]. In each time step, the temperature and flow field are calculated and Fourier-transformed to determine the spectral components. Using commercial computational fluid dynamics (CFD) packages in an industrial development environment, the acoustic field is typically not solved directly with the thermal and turbulent flow field, as this would be computationally prohibitive.

Most of the noise in IT equipment (over 95\%) is generated by the fan itself. Aerodynamic noise generated by turbulent flow elsewhere in the system is generally negligible except in regions of high velocity. To account for noise emission in the overall system design, acoustic models should be included with heat transfer and flow modeling, which is computationally very demanding.

\section{Implementing advanced cooling solutions}

Facing this multiscale thermal management challenge, with a wide range of heat fluxes, characteristic length scales, form factors and device platforms, no single cooling solution can cover the entire spectrum. Successful design typically results from appropriate selection from a palette of solutions. 
This section selectively reviews some cooling solutions that can help to address the thermal and energy management challenges outlined in the previous sections. It should be noted that many of these socalled emerging or enabling cooling technologies have been around for more than a decade, yet most have not broken through to off-the-shelf technology. On one hand, this indicates that further research is needed in most areas for these solutions to reach maturity. On the other, a further shift in the balance between computational and communication costs (see Sect. 2.2) might lead to an accelerated introduction of some of these technologies.

As reflected in DARPA's strategy (see Sect. 3.1.1), some key enabling technologies for the coming decade include convective and evaporative microfluidics, enhanced thermal interconnects, and on-chip thermoelectric devices. More than ever, sectors of the market seem ready for active cooling approaches.

\subsection{Air cooling}

\subsubsection{Further optimization of proven technology}

For a chip manufacturer like Intel, air cooling continues to be the preferred cooling method for mainstream CPU products. This is partly due to the recent diversification of mobile platforms, which has led to a wide range of products from the low cost, power-optimized system-on-a-chip (i.e., memory, processor and graphics processor in a single package) to more desktop-oriented CPUs with one to eight cores. This market diversification brings unique challenges. Although air cooling remains the method of choice, Intel has expressed an interest in enabling innovative energy-efficient cooling solutions, as soon as cost-effectiveness tips the balance.

There is a growing trend towards board-level air flow design and control, as exemplified by Sony's graphics server featuring ducted airflow design to direct flow to the hot spots, temperature-based system fan speed, and individual fan control for processors and memory bank to minimize the total fan power and noise emission [73]. This approach could be extended to rack-level hierarchical active cooling using any of the cooling methods described in the following sections.

Alcatel-Lucent has been researching novel manufacturing techniques to produce monolithic enhanced surface area heat sinks with embedded structures to promote vortex shedding and turbulence generation [74]. This involves many manufacturing issues and can be more costly than standard parallel fin or pin fin heat sink designs, but may be enabled by emerging developments in accurate and low-cost 3D metal printing technologies. The more advanced designs have a lower thermal resistance albeit usually at a penalty of increased pumping power [74]. This coupling between heat transfer and momentum transfer (i.e., pumping power) is related to the Reynolds and Chilton-Colburn j-factor analogies, and has long been a physical bottleneck in thermal management. Some alternative air mover technologies that actively cause temporal regeneration of boundary layers (e.g., piezo fans and synthetic jets - see following sections) may change this coupling between heat transfer and momentum transfer and open up more opportunities than passive methods (spatial regeneration of boundary layers). 
As discussed in Sect. 3.2.2, acoustic noise emission is an often-overlooked challenge in air cooled systems. Based on Huawei's projection of the IT equipment power density evolution, the acoustic noise emission level will increase by about $0.5 \mathrm{~dB}(\mathrm{~A})$ per year. Since the current emission levels are already close to the limits prescribed by NEBS in North America and ETSI and ISO in Europe [59,64], there is a need for novel noise-reducing technology, although some major proponents of lean air-cooled data centers (e.g., Google, Microsoft) might also be inclined towards a relaxation of the noise emission limits.

To extend the life of air cooling in telecommunication and data centers, the following targets are proposed:

(i) System level: more efficient air movers to increase the coefficient of performance (COP) above 20, as well as reduce the noise of single fans to below $60 \mathrm{~dB}(\mathrm{~A})$. As indicated in Sect. 3.2.2, acoustics experts are not optimistic about meeting these requirements, although there is some room for improvement if the unit cost can increase.

(ii) Board level: heat sinks with low pressure drop and thermal resistance, e.g., $0.08 \mathrm{~K} / \mathrm{W}$ at 140 cubic feet per minute (66 liter per second) for a $1 \mathrm{U}$ (rack unit) form factor device. As mentioned above, the coupling between heat and momentum transfer is the main physical restriction for this requirement, yet alternative air moving techniques (see following sections) may provide a way to circumvent this restriction.

(iii) Component level: no further increase in component power and a reduction in component thermal resistance.

If air cooling would indeed become untenable, a choice will have to be made between restricting the power density or resorting to liquid cooling. However, considering the potential advances of alternative air cooling techniques, and considering the history of past predictions about the demise of air cooling, this horizon may prove to be quite flexible.

\subsubsection{Alternative air movers: Piezo fans}

For Intel, the main parameters driving cooling technology are thermal performance, cost, system size, acoustics, and energy consumption. In the palette of available solutions, piezoelectrically actuated vibrating cantilever fans (or piezo fans) offer a viable option for small form factor and low power (below $40 \mathrm{~W}$ ) platforms. Passive and active heat sinks have an overlap zone in the $15-40 \mathrm{~W}$ range. A cooling approach using piezo fans that provides cooling in this range and has less system dependency can promote design flexibility.

The main advantages of piezo fans are low cost, low power consumption, low noise, good reliability, and good thermal performance in the low to moderate heat flux range $\left(0.1-1 \mathrm{~W} / \mathrm{cm}^{2}\right)$ [75-77]. Piezo fans can be used to replace or augment traditional air flow movers like axial fans, and equivalent fan curves can be established for them [76]. A comparative study by Intel for a chipset heat sink cooled by axial fans and by a number of piezo fans showed that the piezo fans require $50 \%$ less power to achieve the same thermal performance and the same noise level as the conventional fan-based cooler [78]. These devices 
can be combined with existing speed-controlled axial fans to achieve significant gains in heat transfer performance when the fans are operated at lower speeds.

\subsubsection{Alternative air movers: Synthetic jets}

As with piezo fans, synthetic jets can significantly increase the convective heat transfer rate by effecting a temporal breakup and thinning of the thermal boundary layer, and enhancing the entrainment of surrounding air. 'Synthetic' refers to the jet flow being synthesized from the surrounding air by periodic suction and blowing of air across an orifice. Like piezo fans, synthetic jet actuators use robust and energy efficient piezoelectric actuators [79], without any rotating parts. Unlike steady jets (such as those used for turbine blade cooling, manufacturing processes, and micro-scale electronics cooling), synthetic jets do not require an external pressurized fluid source, yet a single impinging synthetic jet can achieve the same convective heat transfer rate as a steady impinging jet at the same Reynolds number [80].

Synthetic jets can help to reduce fan speeds by de-coupling heat transfer and thermal transport, where a low-level fan-driven flow carries heated air out of the equipment, while a number of synthetic jet actuators create local cooling on selected components. The magnitude of the jet flow can be easily controlled, making them suitable for integration in actively controlled cooling schemes. Consisting only of a piezoelectric actuator, a cavity and an orifice, a synthetic jet actuator can be used to augment cooling in confined spaces such as low-height arrangements in telecom applications, or other applications with inherently low mass flow.

These devices are scalable, with an optimal operating frequency that varies proportional to the Helmholtz resonance frequency of the cavity and orifice [79]. In air, the typical cooled area varies from below $1 \mathrm{~cm}^{2}$ to $25 \mathrm{~cm}^{2}$, for a corresponding device volume from $0.1 \mathrm{~cm}^{3}$ to $10 \mathrm{~cm}^{3}$. The desired operating frequency is typically below $200 \mathrm{~Hz}$ or ultrasonic (above $20 \mathrm{kHz}$ ), as exemplified by a range of small ultrasonic synthetic jet actuators (about $0.8 \mathrm{~cm}^{3}$ ) manufactured by Murata [81].

In terms of acoustic noise reduction, a single synthetic jet can reduce the noise emission compared to an axial fan while having the same or better thermal performance [82]. Furthermore, a pair of phasecontrolled adjacent jets has been used successfully to control the angle of the jet flow [83], which provides even more opportunities for active cooling control. Preliminary experiments on this dual jet configuration have shown significant reductions in noise emission by partial noise cancellation.

\subsubsection{Alternative air movers: Ionic wind}

Ionic propulsion of air is established by a corona discharge (using direct current) or a barrier discharge (using alternating current), which make the air electrically conductive and cause subsequent air entrainment as charged ions are attracted towards a ground electrode $[84,85]$. In Ventiva's ionic wind actuator [86], a DC voltage of $3 \mathrm{kV}$ is used with a $1 \mathrm{~mm}$ distance between a metal electrode wire and a ground plane mesh.

The main disadvantages are the low pressure head, the ozone production which may pose a health issue, and reliability issues related to dust fouling and wire breakage. Potential applications include LED 
lighting with an acoustic emission requirement below $30 \mathrm{~dB}$, mini projectors (no sound generated), and mobile electronic devices. In terms of coefficient of performance, Ventiva's fan takes about 0.25-2 $\mathrm{W}$ to cool up to $50 \mathrm{~W}$.

\subsection{Liquid cooling}

There remains a divide between proponents of air cooling and liquid cooling. One group advocates aircooled systems operated at an elevated temperature with minimal overhead, taking maximum advantage of low-temperature climates and alternative ultimate heat sinks. Another group advocates liquid-cooled (or hybrid air/liquid-cooled) systems which enable increased power density $[87,88]$, employing waste heat recovery to maximize energy and exergy efficiency and compensate for the higher capital investment costs of liquid-cooled systems.

Given the low cost of data communication, air cooling remains the preferred method for the majority of the industry, including the recent rise in cloud computing facilities that can be located far from populated areas (i.e., at a low floor space cost), in cooler climates, or close to a cheap electricity supply. For barebones air-cooled data centers running at a PUE value of 1.1-1.2, the cooling fans consume less than $10 \%$ of the server power consumption, which is small incentive to transition to more expensive liquid-cooled systems.

On the other hand, as the cost of energy and the data traffic volume increase, there is a consensus that future data centers will become dominated by energy cost. IBM's solution is to use water cooling at elevated temperatures. At the chip level, the heat transfer occurs at a temperature difference of $20^{\circ} \mathrm{C}$ (instead of around $75^{\circ} \mathrm{C}$ for air cooling) which limits the loss of exergy. At the facility level, the elevated fluid temperature saves on chiller energy and recovers the maximal potential for energy reuse (e.g., domestic heating, and combined heating and cooling). Between IBM's first and second generation hotwater cooled data center systems, the coolant temperature has increased from $60^{\circ} \mathrm{C}$ for Aquasar in ETH Zurich [53] to $70^{\circ} \mathrm{C}$ for SuperMUC in LRZ Munich [54].

The long term future for large-scale telecom and data centers from a hardware point of view is with liquid cooling. Liquid may even be brought in direct contact with the electronics, using dielectric water. Complexity in liquid cooling solutions is introduced by using cold plates, manifolds, flexible connections, etc. Immersion cooling remains the simplest approach, and new ways to use passive immersion cooling could be pursued. Water still stands out as an excellent heat carrier and coolant, so it seems natural to take advantage of these compounding benefits. The preconceptions and concerns with water cooling in the telecom industry are subsiding, and in the coming years we may see a gradual introduction of water cooling not only at the high end, but also in low-end systems. The introduction of reliable water cooling technology has changed this mindset. The basic driver behind business decisions remains total cost of ownership.

One of the key practical issues impeding the introduction of liquid cooling at present is a lack of standardization, as indicated by a recent ASHRAE white paper on liquid cooling [89]. There are some 
guidelines available on liquid cooling, but only relate to the interface between IT equipment and the facility. AT\&T has been pushing for a more comprehensive standard.

\subsection{Other alternative cooling techniques}

Some recent studies have investigated the potential of using a superlattice thermo-electric cooler (TEC) on top of a hot spot, to achieve site-specific cooling. The TEC actively extracts heat from the hotspot area, which allows a significant reduction in pumping power [90,91], making it a relevant technology for both air cooling and liquid cooling approaches, as well as enabling active local cooling control. High performance TECs are expensive and an overall cost analysis should confirm the economic benefits of this technology for a given application, but it might help extend the life of air cooling as the system density increases. Being more expensive, this technology might be more suitable for increasing performance rather than only reducing direct costs.

Hydrophobic surfaces have a number of potential uses in thermal management: enhanced sustained dropwise condensation for two-phase systems, control of evaporative cooling via electrowetting [9294], and augmented liquid return in vapor chambers [95]. In particular, vapor-chamber heat spreaders are widely used at the component level for efficient heat spreading and can work against gravity (up to about $30 \mathrm{~cm}$ at moderate heat inputs). Significant recent research investment and developments have realized very thin (down to $1 \mathrm{~mm}$ ) vapor chambers [96-98] that could be useful in telecom applications, where the board-to-board spacing is very limited. Device thickness is mainly limited because of mechanical strength and the maximum achievable vapor chamber power density (i.e., about 800-1200 $\mathrm{W} / \mathrm{cm}^{2}$ at evaporator heat transfer coefficients of around $\left.300,000 \mathrm{~W} /\left(\mathrm{m}^{2} \mathrm{~K}\right)\right)$.

\section{Conclusions and outlook}

In terms of energy efficiency and sustainability, the power utilization effectiveness (PUE) value of data centers has gained a lot of importance in recent years. Although it is not a perfect metric, it has focused the attention of corporate leadership in the IT industry on the importance of energy efficiency. However in spite of positive messages from some major companies, most data centers are still at PUE values of 2 and above. Low-cost yet robust technology is needed to reduce the overall impact of IT on the environment.

The main underlying driver for progress is the total cost of ownership (TCO), which indirectly depends on the balance between computational and communication costs. As the cost of energy and the data traffic volume increase, the IT community might face a paradigm shift, where the energy costs far exceed the capital investment of the equipment and infrastructure.

Moore's law will evolve and go three-dimensional: Single layer scaling is slowing down, yet stacking of multiple layers and integrating different functions (processing, memory, sensing) allows Moore's law to be extended into the next decades. 
Based on years of incremental evolution and continual improvements to air cooling technology, current IT equipment uses a million-fold larger volume for cooling compared to the size of the actual transistors performing the computations. By thinking outside the box, and reaching across disciplines, future computers might look very different: Liquid cooled systems reusing the majority of the incoming electricity (e.g., IBM Aquasar and SuperMUC) and interlayer-cooled 3D chip stacks, evolving towards bioinspired designs for maximal energy efficiency which approach the functional density and connectivity of biological brains.

\section{Glossary of abbreviations}

$\begin{array}{ll}\text { 3DIC } & \text { Three-dimensional integrated circuit } \\ \text { ASHRAE } & \text { American Society of Heating, Refrigerating and Air-Conditioning Engineers } \\ \text { CapEx } & \text { Capital expenditure } \\ \text { CFD } & \text { Computational fluid dynamics } \\ \text { CMOS } & \text { Complementary metal-oxide semiconductor } \\ \text { COP } & \text { Coefficient of performance } \\ \text { CPU } & \text { Central processing unit } \\ \text { CRAC } & \text { Computer room air conditioning } \\ \text { DARPA } & \text { Defense Advanced Research Projects Agency } \\ \text { DCiE } & \text { Data center infrastructure efficiency } \\ \text { ENIAC } & \text { Electronic Numerical Integrator And Computer } \\ \text { EPA } & \text { Environmental Protection Agency } \\ \text { ETSI } & \text { European Telecommunications Standards Institute } \\ \text { HPC } & \text { High performance computing } \\ \text { flop } & \text { (Number of) floating-point operations } \\ \text { flops } & \text { (Number of) floating-point operations per second } \\ \text { IC } & \text { Integrated circuit } \\ \text { ISO } & \text { International Organization for Standardization } \\ \text { IT } & \text { Information technology } \\ \text { NEBS } & \text { Network Equipment-Building System } \\ \text { OHSA } & \text { Occupational Safety and Health Administration } \\ \text { OpEx } & \text { Operational expenditure } \\ \text { PUE } & \text { Power utilization effectiveness } \\ \text { TCO } & \text { Total cost of ownership } \\ \text { TEC } & \text { Thermo-electric cooler } \\ \text { TSV } & \text { Through-silicon via } \\ \text { U } & \text { Rack unit } \\ \text { UPS } & \text { Uninterruptible power supply }\end{array}$

\section{Acknowledgements}

The authors gratefully acknowledge the contributions of the participants and speakers at the 2nd Workshop on Thermal Management in Telecommunication Systems and Data Centers in Santa Clara, CA, on April 25-26, 2012. Workshop participants included representatives from leading telecommunications 
systems and data center operators, equipment manufacturers, and system integrators (Alcatel-Lucent, Celsia Technologies, Coolit Systems, Fujitsu Advanced Technologies, Japan, Huawei North America, Huawei Sweden, Huawei China, Google, IBM, IBM Hudson Valley Acoustics Lab, IBM Research Lab, Switzerland, Intel, Microsoft, Airedale/Modine Manufacturing (US, UK), Nelson Acoustics, Oracle, Ventiva, Hewlett-Packard Labs, and ASHRAE), the Defense Advanced Research Projects Agency (DARPA), as well as academic research groups (Purdue University, University of California-Santa Cruz, and Trinity

College Dublin). Dr. Tim Persoons acknowledges funding from the Irish Research Council and FP7 Marie Curie Actions.

\section{References}

[1] Koomey JG. Worldwide electricity used in data centers. Environ Res Lett 2008; 3(3):034008.

[2] Koomey JG. Growth in data center electricity use 2005 to 2010 . Analytics Press, August $1,2011$.

[3] International Energy Agency. Key World Energy Statistics, 2010 (Retrieved October 8, 2012 from www.iea.org).

[4] International Energy Agency. Energy Balances of OECD Countries, 2010 (Retrieved October 8, 2012 from www.iea.org).

[5] International Energy Agency. Energy Balances of Non-OECD Countries, 2010 (Retrieved October 8, 2012 from www.iea.org).

[6] Turner V, Bigliani R, Ingle C. White paper: Reducing greenhouse gases through in tense use of information and communication technology: Part 1. International Data Corporation, Framingham, MA, November 2009.

[7] Policy statement on green ICT. Australian Computer Society, August 2007.

[8] Brill KG. White Paper: Data center energy efficiency and productivity. The Uptime Institute, Inc., Santa Fe, NM, February 2007.

[9] Gartner, Inc. Press release, Stamford, CT, September 29, 2010.

[10] Horvath A, Masanet E. An analysis of measures to reduce the life-cycle energy consumption and greenhouse gas emissions of California's personal computers. University of California Energy Institute, Berkeley, CA, January 2007.

[11] Belady C, Rawson A, Pflueger J, Cadir T. The Green Grid data center power efficiency metrics: PUE and DCiE. The Green Grid: White Paper \#6, 2008.

[12] Energy Star for data centers. U.S. Environmental Protection Agency, February 2010.

[13] ESIF high performance computing. U.S. Department of Energy, National Renewable Energy Laboratory, Golden, CO, October 2011. 
[14] Shah AJ, Bash CE, Kumari N, Cader T, Breen TJ, Walsh E, Punch J, On the need for energy efficiency metrics that span integrated IT-facility infrastructures. Proc ASME 2011 Pacific Rim Technical Conference and Exhibition on Packaging and Integration of Electronic and Photonic Systems (InterPACK), 2011, Paper IPACK2011-52140.

[15] Hoover C, Kumari N, Felix CJ, Bash CE. A data center environmental advisory system. Proc ASME 2011 Pacific Rim Technical Conference and Exhibition on Packaging and Integration of Electronic and Photonic Systems (InterPACK), 2011, Paper IPACK201152128.

[16] Sharma RK, Bash CE, Patel CD. Dimensionless parameters for evaluation of thermal design and performance of large-scale data centers. Proc ASME/AIAA Joint Thermophysics and Heat Transfer Conf, 2002, Paper AIAA-2002-3091.

[17] VanGilder JW, Shrivastava SK. Real-time prediction of rack-cooling performance. ASHRAE Trans 2006; 112(2):151-62.

[18] Bash C, Forman G. Data center workload placement for energy efficiency. Proc ASME International Electronic Packaging Technical Conference and Exhibition (InterPACK), 2007, p. 733-41.

[19] Kumari N, Shah A, Bash C, Chen Y, Liu Z, Wang Z, Cader T, Slaby M, Cepulis D, Felix C, Aviles A, Figueroa M. Optimizing data center energy efficiency via ambient-aware IT workload scheduling. Proc Intersoc Conf Thermal and Thermomechanical Phenomena in Electronics Systems (ITHERM), 2012, Paper 2867.

[20] Chen Y, Gmach D, Hyser C, Wang Z, Bash C, Hoover C, Singhal S. Integrated management of application performance, power and cooling in data centers. Proc 12th IEEE/IFIP Network Operations and Management Symposium (NOMS), April 2010.

[21] IBM system X M4 servers deliver compelling performance and energy efficiency. IBM White Paper, March 2012.

[22] Huber $\mathrm{H}$. The petascale power challenge. 3rd European Workshop on HPC Centre Infrastructures, Garching, Germany, September 2011.

[23] TOP500 (www.top500.org), June 2012.

[24] Whitepaper: 2011 Thermal Guidelines for Data Processing Environments - Expanded Data Center Classes and Usage Guidance. ASHRAE Technical Committee 9.9, 2011.

[25] IBM Comments on Energy Star server specifications: Revised definitions for computer servers. IBM, May 12, 2008 (Retrieved November 19, 2012 from http://www.energystar.gov/ia/partners/prod_development/new_specs/downloads/IBM _Comments_Revised_Definitions.pdf).

[26] Blarke MB, Yazawa K, Shakouri A, Carmo C. Thermal battery with $\mathrm{CO}_{2}$ compression heat pump: Techno-economic optimization of a high-efficiency Smart Grid option for buildings. Energy and Buildings 2012; 50:128-38. 
[27] District Heating and Cooling - 2009 Statistics, Euroheat \& Power (Retrieved November 19, 2012 from

http://www.euroheat.org/Admin/Public/DWSDownload.aspx?File=\%2fFiles\%2fFiler\%2fd ocuments\%2fDistrict+Heating\%2fDHC_2009_Statistics_Table.pdf).

[28] Eurostat. Electricity half-yearly prices. European Commission, Mar 27, 2009 (Retrieved October 1, 2012 from epp.eurostat.ec.europa.eu/portal/page/portal/energy/data/database).

[29] Tiwari MK, Zimmermann S, Sharma CS, Alfieri F, Renfer A, Brunschwiler T, Meijer I, Michel B, Poulikakos D. Waste heat recovery in supercomputers and 3D integrated liquid cooled electronics. Proc 13th IEEE Intersoc Conf Thermal and Thermomechanical Phenomena in Electronic Systems (ITHERM), 2012, p. 545-51.

[30] Kennedy J. Intel futurist Brian David Johnson on creating the tech of tomorrow. Siliconrepublic.com, July 26, 2012 (Retrieved July 27, 2012 from www.siliconrepublic.com/digital-21/item/28510-intel-futurist-brian-david/).

[31] Mobile phone access reaches three quarters of planet's population (Press release). The World Bank, Washington, DC, July 17, 2012 (Retrieved July 27, 2012 from www.worldbank.org/en/news/2012/07/17/mobile-phone-access-reaches-threequarters-planets-population).

[32] Bakken R. Energy-efficient management of a world class global network. Samsung Semiconductor CIO Forum, Munich, Germany, April 13, 2011.

[33] Inside one of the world's largest data centers. CNET, November 2, 2009 (Retrieved July 7, 2012 from news.cnet.com/8301-13860_3-10371840-56.html).

[34] Inside Microsoft's new Quincy cloud farm. Data Center Knowledge, January 4, 2011 (Retrieved July 7, 2012 from www.datacenterknowledge.com/inside-microsofts-newquincy-cloud-farm/).

[35] Garimella SV, Yeh L-T, Persoons T. Thermal management challenges in telecommunication systems and data centers. IEEE Trans Compon Packag Manuf Technol 2012; 2(8):1307-16.

[36] Michel B. Roadmap towards ultimately efficient datacenters. IBM, May 4, 2012 (Retrieved October 8, 2012 from www950.ibm.com/events/wwe/grp/grp011.nsf/vLookupPDFs/Roadmap_Towards_Ultimately_ Efficient_Datacenters_20120430_V1/\$file/Roadmap_Towards_Ultimately_Efficient_Data centers_20120430_V1.pdf)

[37] Ruch P, Brunschwiler T, Escher W, Paredes S, Michel B. Towards five-dimensional scaling: How density improves efficiency in future computers. IBM J Res Development 2011; 55(5):15:1-15:13.

[38] IBM, Press Release, Armonk, NY, June 9, 2008 (Retrieved November 19, 2012 from http://www-03.ibm.com/press/us/en/pressrelease/24405.wss). 
[39] Merkle RC. Energy limits to the computational power of the human brain. Foresight Update 6, Foresight Institute, August 1, 1989.

[40] Unlocking energy efficiency in the U.S. economy. McKinsey \& Co., July 2009.

[41] Weik MH. A survey of domestic electronic digital computing systems. US Department of Commerce, Ballistic Research Laboratories Report No. 971, December 1955, p. 41 (Retrieved July 26, 2012 from ed-thelen.org/comp-hist/BRL.html)

[42] Schmidt RR. Liquid cooling is back. Electronics Cooling, August, 2005.

[43] Sri-Jayantha SM, McVicker G, Bernstein K, Knickerbocker JU. Thermomechanical modeling of 3D electronic packages. IBM J Res Development 2008; 52(6):623-34.

[44] Alfieri F, Tiwari MK, Zinovik I, Poulikakos D, Brunschwiler T, Michel B. 3D integrated water cooling of a composite multilayer stack of chips. Proc 14th Int Heat Transfer Conf (IHTC14), 2010, Paper IHTC14-22812.

[45] Cray-3 supercomputer systems. Cray Computer Corporation, Colorado Springs, CO, August 1993 (Retrieved July 27, 2012 from archive.computerhistory.org/resources/access/text/2010/02/102685990-05-01-acc. pdf).

[46] ICECool to crack thermal management barrier, enable breakthrough electronics (Press release). DARPA, Arlington, VA, June 7, 2012 (Retrieved July 27, 2012 from www.darpa.mil/NewsEvents/Releases/2012/06/07.aspx).

[47] Kogge P, Bergman K, Borkar S, Campbell D, Carlson W, Dally W, et al. ExaScale computing study: Technology challenges in achieving exascale systems. DARPA Report, September 28, 2008.

[48] Alfieri F, Tiwari MK, Zinovik I, Brunschwiler T, Michel B, Poulikakos D. On the significance of developing boundary layers in integrated water cooled 3D chip stacks. Int J Heat Mass Transfer 2012; 55(19-20):5222-32.

[49] Brunschwiler T, Paredes S, Drechsler U, Michel B, Wunderle B, Reichl H. Extended tensor description to design non-uniform heat-removal in interlayer cooled chip stacks. Proc 13th IEEE Intersoc Conf Thermal and Thermomechanical Phenomena in Electronic Systems (ITHERM), 2012, p. 574-87.

[50] Colgan EV, Bezama RJ, Gaynes M, Marston KC. A practical implementation of silicon microchannel coolers. Electronics Cooling, November 2007.

[51] Wei J. Hybrid cooling technology for large-scale computing systems: from back to the future. Proc ASME 2011 Pacific Rim Technical Conference and Exhibition on Packaging and Integration of Electronic and Photonic Systems (InterPACK2011), 2011, p. 107-11.

[52] Ellsworth MJ, Campbell LA, Simons RE, lyengar MK, Schmidt RR, Chu RC. The evolution of water cooling for IBM large servers: back to the future. Proc 11th Intersoc Conf on Thermal and Thermomechanical Phenomena in Electronic Systems (ITHERM), 2008, p. 266-74. 
[53] Made in IBM labs: IBM hot water-cooled supercomputer goes live at ETH Zurich (Press release). IBM, Zurich, Switzerland, July 2, 2010 (Retrieved July 27, 2012 from www03.ibm.com/press/us/en/pressrelease/32049.wss).

[54] First commercial IBM hot-water cooled supercomputer to consume $40 \%$ less energy (Press release). IBM, Munich, Germany, June 18, 2012 (Retrieved July 27, 2012 from www-03.ibm.com/press/us/en/pressrelease/38065.wss).

[55] Kumari N, Bahadur V, Hodes M, Salamon T, Kolodner P, Lyons A, Garimella SV. Analysis of evaporating mist flow for enhanced convective heat transfer. Int J Heat Mass Transfer 2010; 53:3346-56.

[56] ISO 3744:2010 - Acoustics: Determination of sound power levels and sound energy levels of noise sources using sound pressure - Engineering methods for an essentially free field over a reflecting plane. International Organization for Standardization, September 2010.

[57] ISO 3741:2010 - Acoustics: Determination of sound power levels and sound energy levels of noise sources using sound pressure - Precision methods for reverberation test rooms. International Organization for Standardization, September 2010.

[58] ISO 11201:2010 - Acoustics: Noise emitted by machinery and equipment - Determination of emission sound pressure levels at a work station and at other specified positions in an essentially free field over a reflecting plane with negligible environmental corrections. International Organization for Standardization, May 2010.

[59] ISO 7779:2010 - Acoustics: Measurement of airborne noise emitted by information technology and telecommunications equipment. International Organization for Standardization, July 2010.

[60] Standard ECMA-74: Measurement of Airborne Noise emitted by Information Technology and Telecommunications Equipment, 11th edition. European Computer Manufacturers Association (ECMA), Geneva, Switzerland, December 2010.

[61] ISO 10302:1996 - Acoustics: Method for the measurement of airborne noise emitted by small air-moving devices. International Organization for Standardization, January 2011.

[62] ISO 9296:1988 - Acoustics: Declared noise emission values of computer and business equipment. International Organization for Standardization, February 1998.

[63] Statskontoret Technical Standard 26:6 Acoustical Noise Emission of Information Technology Equipment. Statskontoret (Swedish Agency for Public Management), July 2004.

[64] ETS 300753 - Equipment Engineering (EE): Acoustic noise emitted by telecommunications equipment. European Telecommunications Standards Institute, October 1997.

[65] OHSA Regulation 1910.95 Occupational noise exposure. Occupational Safety and Health Administration, December 2008. 
[66] Council Directive 89/391/EEC on the introduction of measures to encourage improvements in the safety and health of workers at work. European Agency for Safety and Health at Work, June 1989.

[67] Lyon RH, Bergles AE. Noise and cooling in electronics packages. IEEE Trans Compon Packag Technol 2006; 29(3):535-42.

[68] Wakil J, Questad D, Gaynes M, Hamann H, Weger A, Wang M, et al. Thermal development, modeling and characterization of the cell processor module. Proc 10th Intersoc Conf Thermal and Thermomechanical Phenomena in Electronics Systems (ITHERM), 2006, p.289-96.

[69] Kaplan JM, Forrest W, Kindler N. Revolutionizing data center energy efficiency. McKinsey \& Co., July 2008.

[70] Hughes J. Google's new Finland data center is cooled by Baltic Sea's water (Press release). Digitaltrends.com, May 24, 2011 (Retrieved July 27, 2012 from www.digitaltrends.com/computing/googles-new-finland-data-center-is-cooled-by-balticseas-water/)

[71] Fehrenbacher K. The alternative option for energy storage makers: off-grid. Gigaom.com, June 21, 2011 (Retrieved July 30, 2012 from gigaom.com/cleantech/the alternative-option-for-energy-storage-makers-off-grid/)

[72] Wang Y, Lee HC, Li KM, Gu Z, Chen J. Experimental and numerical study of flow over a cavity for reduction of buffeting noise. Acta Acust united Ac 2012; 98(4): 600-10.

[73] Sony. BCU-100 Computing Unit with Cell/B.E. and RSX. White Paper. Sony Corporation, 2008 (Retrieved July 30, 2012 from pro.sony.com/bbsccms/ext/ZEGO/files/BCU100_Whitepaper.pdf)

[74] Krishnan S, Hernon D, Hodes M, Mullins J, Lyons AM. Design of complex structured monolithic heat sinks for enhanced air cooling. IEEE Trans Compon Packag Manuf Technol 2012; 2(2):266-77.

[75] Acikalin T, Garimella SV. Analysis and prediction of the thermal performance of piezoelectrically actuated fans. Heat Transf Eng 2009; 30(6):487-98.

[76] Kimber ML, Suzuki K, Kitsunai N, Seki K, Garimella SV. Pressure and flow rate performance of piezoelectric fans. IEEE Trans Compon Packaging Technol 2009; 32(4):766-75.

[77] Kimber ML, Garimella SV. Cooling performance of arrays of vibrating cantilevers. J Heat Transfer-Trans ASME 2009; 131(11): 111401.

78 Sauciuc I, Gupta A. Electronics cooling advancements, challenges and innovation needs: System/chip level thermal management. In: 2nd Workshop on Thermal Management in Telecommunication Systems and Data Centers in Santa Clara, CA, April 25-26, 2012.

[79] Persoons T. General reduced-order model to design and operate synthetic jet actuators. AIAA J 2012; 50(4):916-27. 
[80] Persoons T, McGuinn A, Murray DB. A general correlation for the stagnation point Nusselt number of an axisymmetric impinging synthetic jet. Int J Heat Mass Transfer 2011; 54(17-18):3900-8.

[81] Murata. Features and Technical Specifications of Microblower. Murata Manufacturing Company, Ltd. (Retrieved July 30, 2012 from www.murata.com/products/micromechatronics/feature/microblower/index.html)

[82] Mahalingam R, Heffington S, Jones L, Williams R. Synthetic jets for forced air cooling of electronics. Electronics Cooling, 2007, p. 2-5.

[83] Persoons T, O'Donovan TS, Murray DB. Heat transfer in adjacent interacting impinging synthetic jets. Proc ASME Summer Heat Transfer Conference (HT2009), 2009, Vol. 1, p. 955-62.

[84] Go DB, Garimella SV, Fisher TS, Mongia RK. Ionic winds for locally enhanced cooling. J Appl Phys 2007; 102(5): 053302.

[85] Go DB, Maturana RA, Fisher TS, Garimella SV. Enhancement of external forced convection by ionic wind. Int J Heat Mass Transfer 2008; 51(25-26): 6047-53.

[86] Schlitz DJ, Singhal V. An electro-aerodynamic solid state fan and cooling system. Proc 24th IEEE Semiconductor Thermal Measurement and Management Symposium (SEMITHERM), 2008, p. 46-9.

[87] Harirchian T, Garimella SV. A comprehensive flow regime map for microchannel flow boiling with quantitative transition criteria. Int J Heat Mass Transfer 2010; 53(13-14): 2694-702.

[88] Garimella SV, Rice RA. Confined and submerged liquid jet impingement heat transfer. J Heat Transfer-Trans ASME 1995; 117(4): 871-7.

[89] ASHRAE. 2011 Thermal Guidelines for Liquid Cooled Data Processing Environments. White Paper, ASHRAE Technical Committee 9.9, American Society of Heating, Refrigerating and Air-Conditioning Engineers, Inc., 2011

[90] Sahu V, Yazawa K, Ziabari A, Shakouri A, Fedorov AG, Joshi Y. Energy efficient liquidthermoelectric hybrid cooling for hot-spot removal. Proc 28th IEEE Semiconductor Thermal Measurement and Management Symposium (SEMI-THERM), 2012, p. 130-134.

[91] Shakouri A. Nanoscale thermal transport and microrefrigerators on a chip. Proc IEEE 2006; 94(8): 1613-38.

[92] Bahadur V, Garimella SV. Electrowetting-based control of static droplet states on rough surfaces. Langmuir 2007; 23(9): 4918-24.

[93] Kumari N, Bahadur V, Garimella SV. Electrical actuation of dielectric droplets. J Micromech Microeng 2008; 18(8): 085018.

[94] Annapragada SR, Dash S, Garimella SV, Murthy JY. Dynamics of droplet motion under electrowetting actuation. Langmuir 2011; 27(13): 8198-204. 
[95] Boreyko JB, Zhao Y, Chen C-H. Planar jumping-drop thermal diodes. Appl Phys Lett 2011; 99(23):234105.

[96] Altman DH, Weibel JA, Garimella SV, Fisher TS, Nadler JH, North N. Thermal ground plane vapor chamber heat spreaders for high power packaging density electronic systems. Electronics Cooling, March 2012; p. 20-7.

[97] Weibel JA, Garimella SV, North MT. Characterization of evaporation and boiling from sintered powder wicks fed by capillary action. Int J Heat Mass Transfer 2010; 53(19-20): 4204-15.

[98] Weibel JA, Garimella SV, Murthy JY, Altman DH. Design of integrated nanostructured wicks for high-performance vapor chambers. IEEE Trans Compon Packag Manuf Technol 2011; 1(6): 859-67.

\section{List of figure captions}

Figure 1. Evolution of the worldwide electricity usage from 2000 until 2010: contribution of data centers $(\triangle)$ compared to the sum of all sectors $(\square)$. Data obtained from [1-5].

Figure 2. Schematic Sankey diagram for a typical present-day data center facility, representing the distribution of power through three main system components (system and rack level IT equipment, cooling infrastructure, electrical power storage and delivery), partly based on data from $[1,2]$.

Figure 3. Evolution of the average power usage effectiveness (PUE) of data centers from 2000 until 2010: Worldwide average $(\triangle)$ and company-average for Google ( $O$ ). Data obtained from [1-5] with estimated values for Google from [2].

Figure 4. Word cloud visualization of the round table discussions at the 2 nd Workshop on Thermal Management in Telecommunication Systems and Data Centers in Santa Clara, CA on April 25-26, 2012 (Image generated by wordle.net).

Figure 5. Schematic Sankey diagram for a 'cloud-optimized' data center using air cooling at an elevated room temperature to maximize the use of free cooling. Compared to a typical data center (Fig. 2), more demanding rack-internal air cooling leads to acoustic noise challenges, which can be partly addressed with advanced air cooling solutions.

Figure 6. Schematic Sankey diagram for a fully liquid-cooled data center, with more efficient high-density rack-level cooling due to the superior heat carrier properties of water. Using water at an elevated temperature, this approach is suitable for waste heat recuperation. 
Figure 1

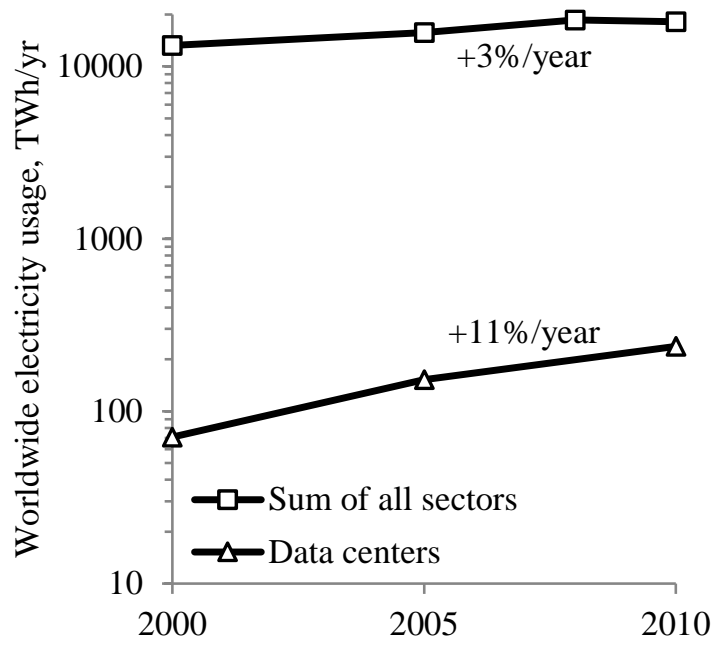


Figure 2

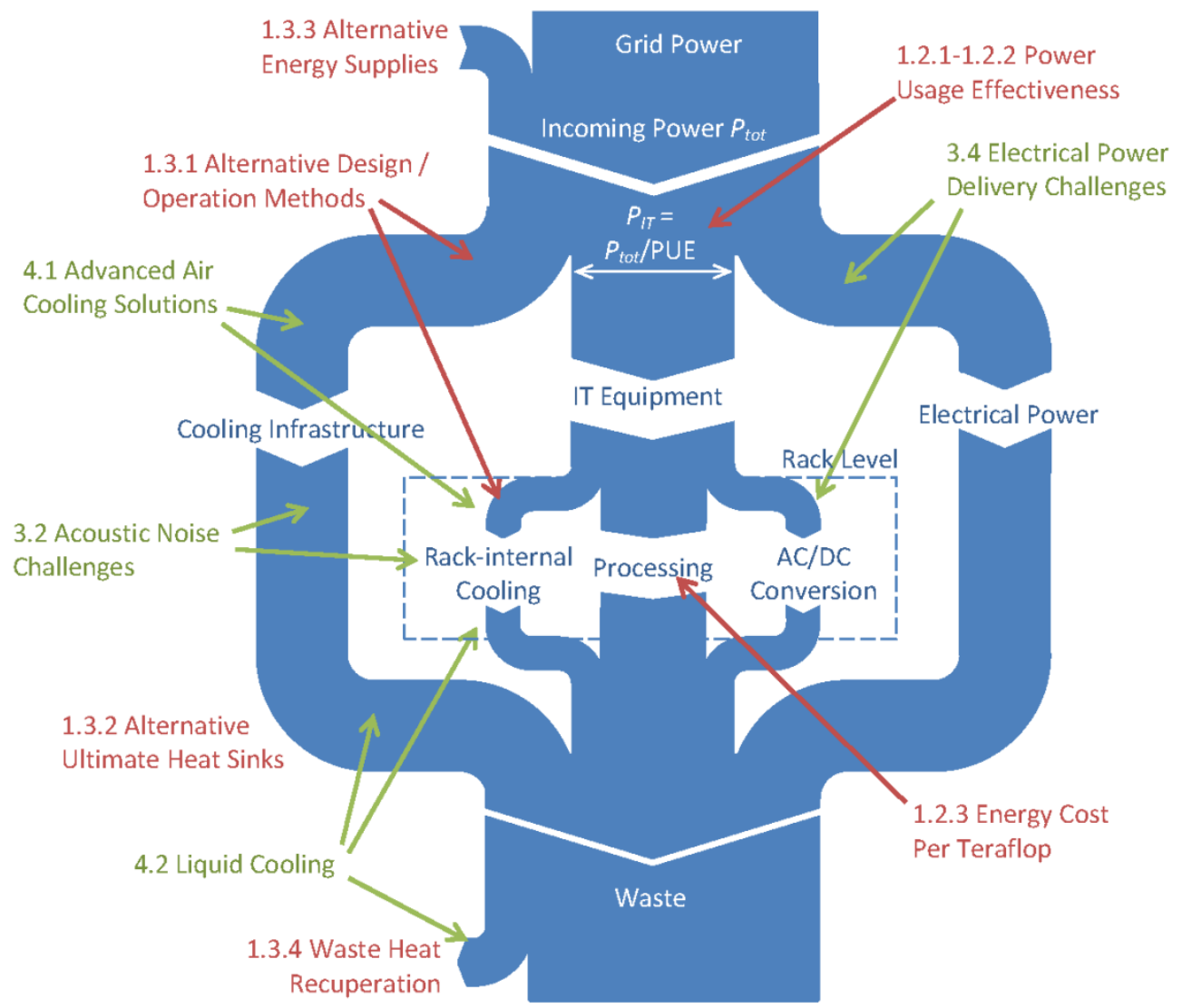


Figure 3

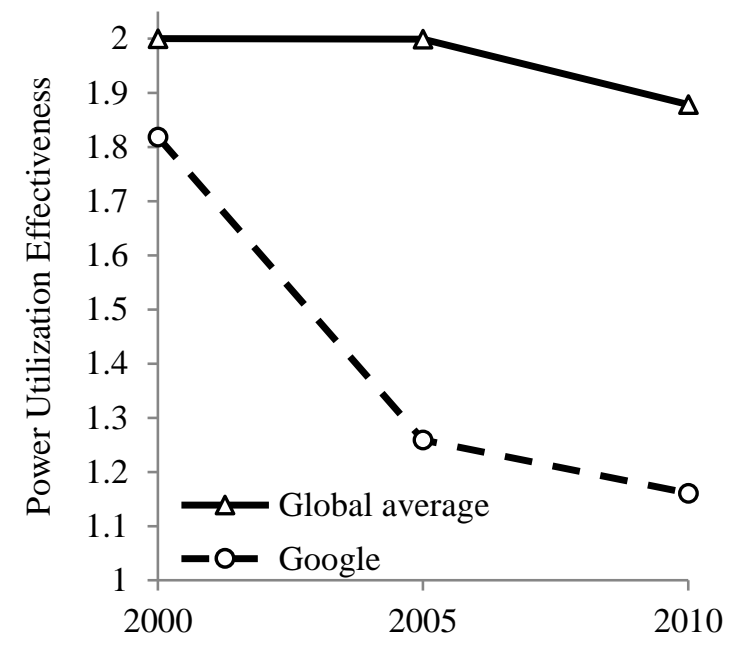


Figure 4

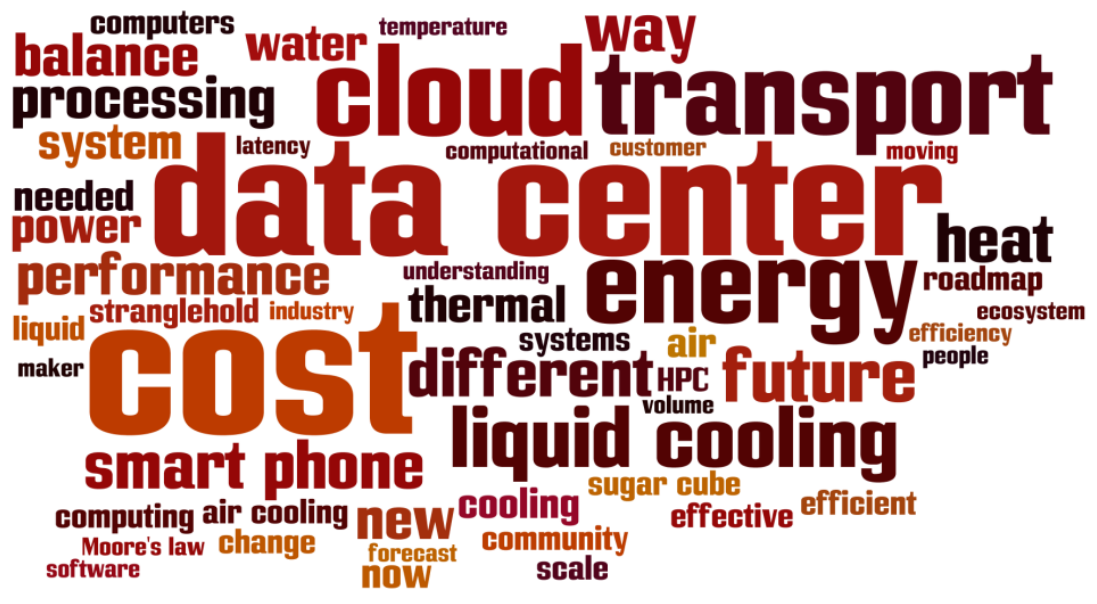




\section{Figure 5}

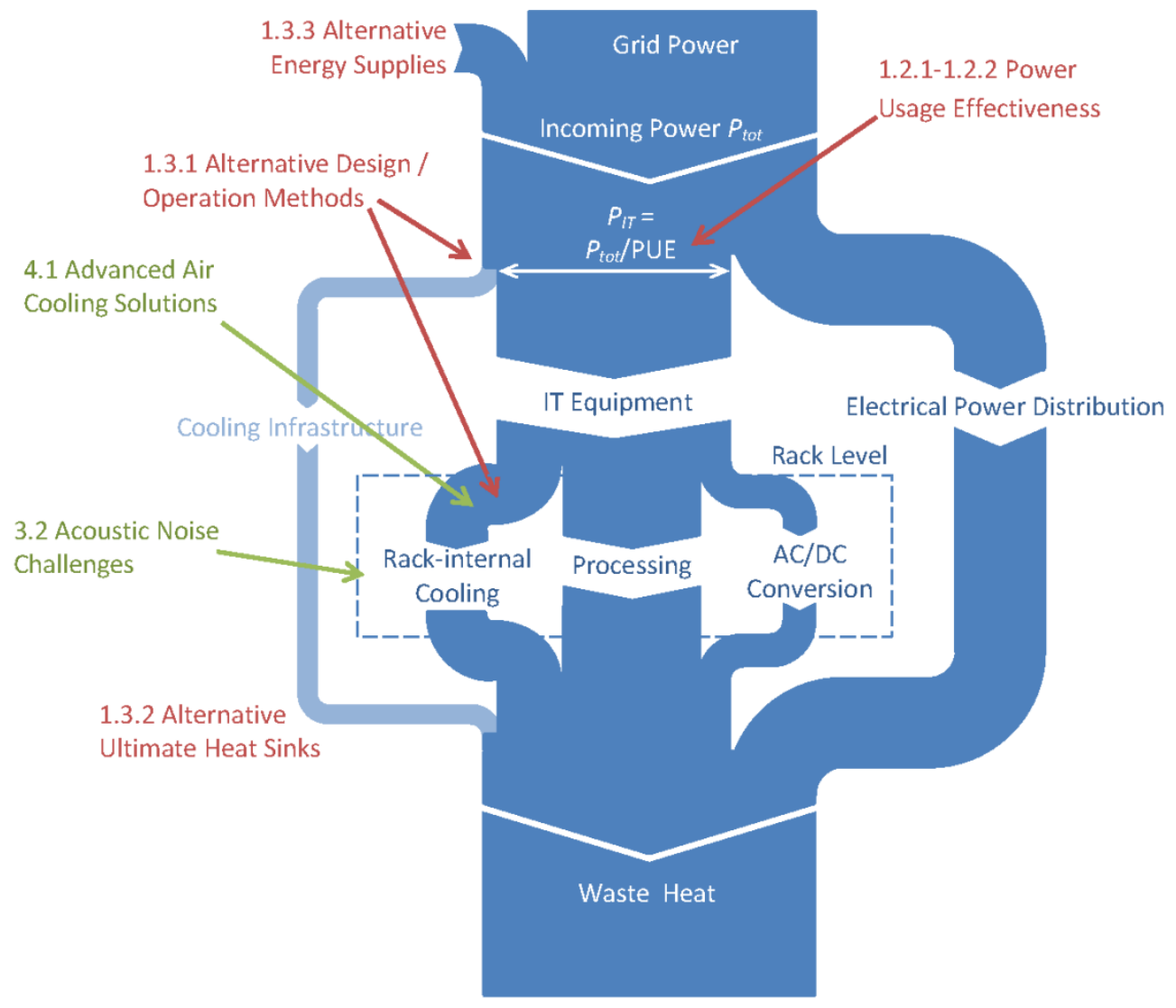




\section{Figure 6}

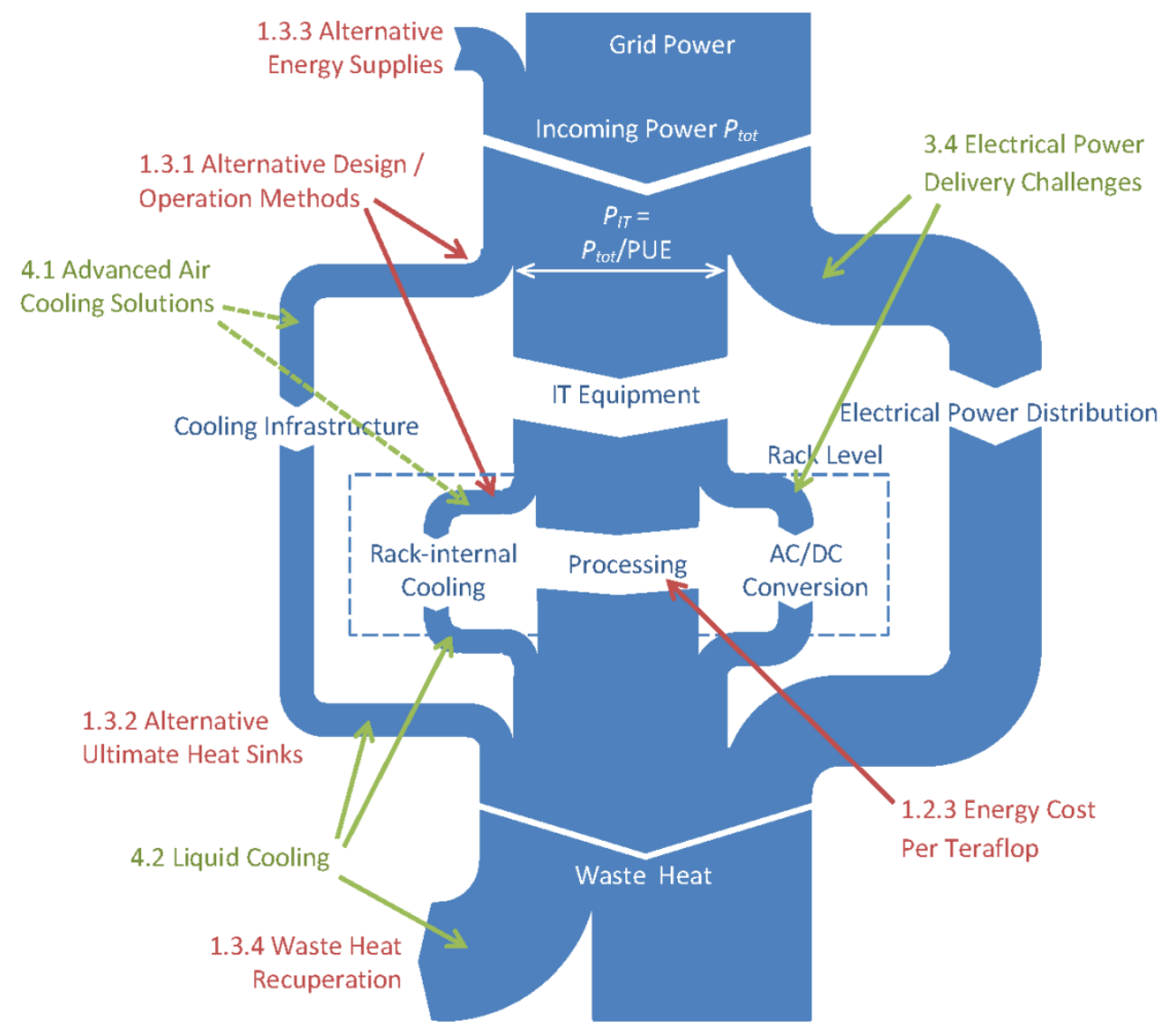

